\title{
MANUEL CANUTO RESTREPO Y VILLEGAS, 1825-1891 UN OBISPO EN GUERRAS CIVILES COLOMBIANAS, ENTRE LA COMUNA DE PARÍS Y LA COMUNA DE PASTO*
}

\author{
Luis Javier Ortiz Mesa*
}

\begin{abstract}
Resumen
Este artículo estudia a un colombiano de la región conservadora de Antioquia, Manuel Canuto Restrepo y Villegas, que se formó como sacerdote y llegó al obispado de la teológica ciudad de Pasto, al sur de los Estados Unidos de Colombia, en 1872. Se comprometió decididamente con la doctrina católica y la sociedad de cristiandad apoyadas en el Syllabus errorum. Luchó por ellas en la guerra y la paz, y batalló asiduamente contra sus opositores, liberales, protestantes, masones y comunistas, quienes, en su concepto, tramaban un complot contra el catolicismo para sustituir a la Iglesia por el libre-pensamiento, el dominio de la razón y el ateísmo. Para ello, fundó una Comuna en Pasto que opuso a la de París y desarrolló múltiples actividades pastorales, siendo un experto en la guerra de la pluma y del anónimo. Aceptada su renuncia por exigencia Papal después de la guerra político-religiosa de 1876-1877, perdió su cargo en 1880 y debió esperar unos años el derrumbe del liberalismo radical (1863-1886) para saborear las mieles de la Regeneración conservadora, prohispánica y católica, antes de su muerte en 1891.
\end{abstract}

Palabras clave: historia de la Iglesia católica, historia política, historia de Colombia, obispos, guerras civiles, Pasto (Colombia), siglo XIX, La Comuna de París, La Comuna de Pasto.

\begin{abstract}
This article is about a colombian from the conservative region of Antioquia, his name is Manuel Canuto Restrepo and Villegas, he formed himself as a priest and became a bishop from the theological city of Pasto in 1872. He decidedly committed himself with the catholic regime -which at the time was privileged by the state-, supported by the Syllabus errorum. He fought for it in times of war and peace, his battles where assiduously against his opponents, liberals, protestants, masons and communists which, in his concept where forming a complot against the catholic religion, to substitute the church for a free thinking with domain of reason and atheism. To neutralize these he founded a community in Pasto that opposed to the one in Paris and developed multiple pastoral activities do to the fact that he was an expert in fighting a war with the pen and anonymity. Once his renounce was accepted by a papal requirement after the political and religious war of 1876-1877, he lost his position in 1880 and he had to wait several years -before his death in 1891-, until the

\footnotetext{
"Artículo de investigación tipo 2: de reflexión según Colciencias. Hace parte de la Investigación "La Guardia Nacional y los Ejércitos Federales de los Estados Soberanos de la Confederación Granadina y de los Estados Unidos de Colombia, 1855-1885" (Colciencias, código 1102-452-21348), desarrollado por las Universidades Industrial de Santander (UIS), Pedagógica y Tecnológica de Colombia (UPTC) y Nacional de Colombia, Sede Medellín (Grupo interuniversitario "Religión, Cultura y Sociedad"), bajo la dirección del profesor Juan Alberto Rueda Cardozo de la UIS.

*** Profesor Titular del Departamento de Historia, de la Universidad Nacional de Colombia, Sede Medellín. E-mail: afrodita@une.net.co.
} 
fall of the radical liberalism (1863-1886) in order to be able to taste the delights of the conservative regeneration, pro-hispanic and catholic.

Key words: Story of the Catholic Church, political history, Colombian history, bishops, civil wars, Pasto (Colombia), $19^{\text {th }}$ century, The Paris Commune, The Pasto Commune.

\section{Introducción}

La Comuna de París se desarrolló durante los meses de marzo a mayo de 1870, mientras la Comuna de Pasto tuvo vida entre 1874 y 1875. La primera estableció un gobierno popular mediante una insurrección de trabajadores, oficinistas, funcionarios, pequeños tenderos y artesanos -de muebles, artículos de lujo, ropas y zapatos-, que se produjo en el contexto de la guerra Franco-Prusiana, y que dio lugar a una Organización municipal independiente de París (la "Comuna"). Se trató de una cooperativa autónoma o unidades corporativas de productores, cuyo poder efectivo cayó en manos de los alcaldes de los distritos, la Guardia nacional y los obreros, quienes fueron derrotados, exiliados y asesinados por el gobierno republicano de Versalles, representante de la burguesía parisina (Hobsbawm, 1989, pp. 165-167). En cambio, la Comuna de Pasto fue el resultado de un movimiento social de carácter conservador y católico, en defensa de la Iglesia, ante el supuesto complot del liberalismo, heredado de la Revolución Francesa, para destruirla, liderado por el obispo de Pasto, Manuel Canuto Restrepo y Villegas.

El obispo, al volver del Concilio Vaticano I realizado en Roma en 1870, después de ser ungido por el papa Pío IX como prelado y de conocer en Europa los sucesos de la Comuna de París, volvió a los Estados Unidos de Colombia dirigidos por el liberalismo radical y fundó una Comuna católica en Pasto que opuso a la de París, por considerarla "atea, revolucionaria y comunista" y una "amenaza internacional al orden y la civilización” (Hobsbawm, 1989, pp. 165). El obispo Restrepo percibió la Comuna de París como uno de los principales males de la época y como la más explícita demostración de anarquismo, incredulidad y desorden social y moral. Consideraba urgente llamar la atención de los que, en su opinión, eran los mismos males que debilitarían y destruirían el régimen de cristiandad y el poder temporal de la Iglesia en occidente, dentro de su visión apocalíptica y complotista acerca del liberalismo (González, 2006, p.46) y "las demás sectas del mal", entre las que destacaba la masonería, el protestantismo, el socialismo y el comunismo. Se trataba de los errores modernos expuestos en el Syllabus errorum de 1864 (Arango de Restrepo \& Arboleda Mora, 2005, pp. 87-155). Contra tales errores, debía librarse un combate a muerte, tal como el mismo obispo lo hizo a su regreso de Europa a América.

El obispo Restrepo, llegaba bien preparado del Concilio Vaticano I, para luchar por la fe suya y la de sus feligreses. Leyó de nuevo y con cuidado los Decretos del Primer Sínodo Provincial de la Nueva Granada de 1868, firmados por el arzobispo de Bogotá, Vicente Arbeláez y los demás obispos del país, los cuales se constituyeron en nuevas directrices de sus conductas, tal como numerosos documentos pontificios y episcopales lo habían hecho desde su formación. Pero Restrepo seleccionó con cuidado los rasgos sobre los cuales pondría un énfasis especial. El capítulo II, acerca de los Obispos, era decisivo: "El Señor estableció a los Obispos como atalayas para que cuando vean venir la espada toquen la 
trompeta y exhorten a los pueblos... Deben conservar íntegro y puro hasta el fin el depósito de la fe y de la tradición, para que no se corrompa con errores y falsas opiniones; valiéndose de los medios oportunos para impedir que la grey que les está confiada perezca eternamente" (Actas y decretos del Concilio Primero Provincial Neo-granadino, 1869, p. 39). Además, los obispos gobiernan la Iglesia, tienen un cuidado paternal por los necesitados y ejercen su papel de jueces en su diócesis, pues "Toca a ellos amonestar y corregir intrépidamente a los transgresores y someterlos a las penas canónicas, juzgando siempre sin pasión, pues a ellos se les ha dicho: Rogad, amonestad con toda paciencia y doctrina" (Actas y decretos del Concilio Primero Provincial Neo-granadino, 1869, p. 40).

Como otros hermanos suyos en el episcopado en distintos países latinoamericanos ${ }^{1}$, el obispo Restrepo se constituyó en un adalid en la defensa de la Iglesia católica, y asumió su mandato como una cruzada religiosa contra el liberalismo. El obispo se sentía un Macabeo en medio de un pueblo elegido, al cual liberaría mesiánicamente del pecado y la persecución ("Libros de los Macabeos", Biblia de Jerusalén, 1967, pp. 543-599). Por ello afirmaba en su pastoral del 12 de octubre de 1872, al referirse a los creyentes, que se habían corrompido y no hacían el bien; y de los "enemigos de la Iglesia", que "tienen al cinto provisión de veneno y puñal; llevan en una mano el martillo demoledor y en la otra la tea incendiaria, y van gritando libertad, igualdad y fraternidad" (Rincón, 1940, p.31).

\section{Niño, sacerdote, párroco y procurador}

Manuel Canuto Restrepo y Villegas (Agreda, 1998, pp.107-146; Rincón, 1940, pp.1-56; Ortiz, 1935; BRP, Centro Cultural Leopoldo López Álvarez), nació en 1825 en el distrito antioqueño de Abejorral, una de las poblaciones fundadas a comienzos del siglo XIX, como resultado de la colonización que se desplazó del oriente al sur de Antioquia. Contaba con hermanos prestigiosos. Venancio era un importante jurisconsulto, José de la Cruz se destacó en la administración estatal, Servando fue el padre de Juan Pablo Restrepo -connotado político y escritor, autor del libro sobre la Iglesia y el Estado en Colombia publicado en 1885 en París-, Alejandro fue un militar sobresaliente, y José Antonio fue colega suyo en el sacerdocio. Su familia era una de las de mayor peso económico y social en el departamento del sur, en donde se destacaba con otras de apellidos Villegas, Arango, Mejía, Restrepo y González. Manuel Canuto realizó sus estudios elementales en una escuela local; más tarde, con el apoyo del obispo de la Diócesis de Antioquia, el liberal santandereano Juan de la Cruz Gómez Plata, fue becado en el Colegio de San Fernando, antes Colegio colonial de los Jesuitas y luego Seminario de Santa Fe de Antioquia, donde tuvo como compañeros a varios de los integrantes del futuro gobierno conservador de Pedro Justo Berrío (1864-1873) (Villegas Botero, 1996), con quien mantuvo vínculos de amistad en un período de predominante federalismo liberal en el país; posteriormente viajó a Bogotá a estudiar en el Colegio Seminario de San Bartolomé, teología, gramática, historia, filosofía y lenguas; consiguió dominar el latín, el griego,

\footnotetext{
1 Algunos de los obispos que tuvieron comportamientos similares a Restrepo y Villegas fueron: Pelagio Antonio de Labastida y Dávalos (1816-1891), obispo de Puebla y arzobispo de México; Dom Antonio de Macedo Costa, obispo de Pará y Dom Frei Vital M. Goncalves de Oliveira, obispo de Olinda en Brasil; Pedro Schumacher del Ecuador y Silvestre Guevara de Caracas. Véase John Lynch, "La Iglesia católica, 1830-1930", Leslie Bethell, ed., Historia de América Latina, Barcelona, Cambridge University, Crítica, 1991, tomo 8: “América Latina, cultura y sociedad, 1830-1930”, pp. 65-122.
} 
el francés y el italiano, lo que le fue de mucha utilidad en su formación y en sus viajes a Europa. Por su estilo y liderazgo, desde muy tempranamente sostuvo correspondencia con sacerdotes, obispos y fieles de distintas partes del país, lo que le permitió obtener una audiencia importante en la Iglesia regional y en otras diócesis. Restrepo fue ordenado sacerdote en Bogotá en el año de 1849, por el obispo Manuel José Mosquera, cuando en la Nueva Granada fueron impulsadas reformas liberales durante el gobierno de José Hilario López (1849-1853) (Molina, 1979, pp. 17-129; Tirado Mejía, 1989, pp. 325-384).

En este contexto, Restrepo se caracterizó por sus actitudes antiliberales y por su intransigencia en defensa de los fueros de la Iglesia ante el poder civil. Precisamente en la guerra civil de 1851 (Ortiz Mesa, 1985; Brew, 1971; Uribe de Hincapié \& López Lopera, 2006, marzo; Melo, 1988; Jurado Jurado, 2008, julio-dic., pp. 43-88), siendo coadjutor de la parroquia de Abejorral, su tierra natal, "[...] provocó la asonada para quitar los fusiles que en junio venían de Sonsón para esta ciudad, anduvo con Borrero, concurrió a los combates i parece tenía el grado de Capitán" (Ortiz Mesa, 1985, p.22). Efectivamente, Restrepo fue nombrado teniente $2^{\circ}$ del cuadro militar del jefe conservador caucano Eusebio Borrero. Con este rango combatió con Braulio Henao de Sonsón, coronel efectivo de la columna restauradora de occidente y con otros compañeros más.

Restrepo fue un párroco muy dinámico en Aguadas, Abejorral, Sonsón y Salamina, todas ellas parroquias de distritos conservadores del sur antioqueño. Ocupó este último curato entre 1856 y 1867, el que conjugó con su participación por algunos períodos como miembro de la Cámara de Representantes durante los años 1856 y 1862. La actividad política del entonces sacerdote Restrepo, en un período marcado por el impulso del régimen federal y por las medidas liberales de tuición y desamortización de bienes de manos muertas, permitieron que conociera de cerca los núcleos del conflicto entre las dos potestades y el estilo de los liberales y de sus copartidarios conservadores para afrontarlo. Ello le dio una experiencia personal que le sería de mucha utilidad en los años venideros y en su episcopado. Entre tanto, Restrepo conjugó su misión pastoral en las parroquias con otras "actividades civilizatorias" (Elías, 1989, p.146). construcciones de templos, capillas, cementerios, escuelas, caminos y puentes, dentro de la idea de cristiandad consistente en que la Iglesia era una institución clave para la construcción del Estado-nación.

En el año de 1855, Restrepo tomó parte en la Constituyente que dio a la Provincia de Antioquia su propia Carta constitucional, una vez reintegrada, después de la división liberal de 1851 en tres provincias, las de Medellín, Córdoba y Antioquia (Brew, 1971, pp.120 y ss.). En 1856, fundó el periódico La Unión Católica de Antioquia, de carácter clerical y conservador, en asocio del presbítero Joaquín Guillermo González, quien más tarde sería obispo de Santa Fe de Antioquia. En la guerra civil de 1860 (Quijano Otero, 1982), Restrepo se desempeñaba como cura de Salamina (Duque Botero, 1974) y, ante su negativa de sometimiento a las medidas de tuición y desamortización, debió abandonar su grey y esconderse de las persecuciones decretadas en el año de 1862 por el General Tomás Cipriano de Mosquera, triunfador en la guerra y nuevo Presidente del país. Culminada la contienda y sustituido el gobierno liberal de Pascual Bravo en Antioquia, a comienzos de 1864, por el golpe de cuartel del conservador Pedro Justo Berrío, el padre Manuel Canuto viajó a Roma y Jerusalén (agosto de 1864-octubre de 1867), 
viaje que lo reafirmó en su visión sobre el papel de la Iglesia en Europa, el Oriente y Colombia, y sobre el cual escribió un libro (BRP, Restrepo, 1871a).

Con ocasión del Primer Concilio Provincial Neogranadino de 1868, Restrepo acompañó como teólogo al obispo de Medellín y Antioquia, Valerio Antonio Jiménez, donde lo nombró su Procurador para que concurriera a las sesiones del Concilio Ecuménico Vaticano I, convocado por el Papa Pío IX. El 25 de marzo de 1870, estando en Roma fue preconizado obispo de Pasto. En julio del mismo año, circuló en Pasto, una hoja volante en papel azul firmada por los conservadores Juan Bautista Zarama y José María Bucheli e individuos de otros bandos políticos en la cual los principales vecinos de la ciudad, felicitaban al nuevo obispo por su elevación a la dignidad episcopal. En una parte de la hoja, se decía que:

...era conocido ya entre nosotros, como el de un ilustrado e impertérrito defensor de los derechos y libertades de la Iglesia Granadina y como el de un varón eminentísimo, capaz de rivalizar en celo y valor heroicos con los Roger, los Castellanos, los Bellos, los Fournetz, los Pancemon, Pacquot y con muchos otros esclarecidos curas franceses, mártires de la Asamblea constituyente de 1791. (Ortiz, 1935, p.165)

Los firmantes, le declararon también veneración, amor y respeto, y elevaron súplicas a Dios por su salud y feliz venida. Más tarde, el 9 de noviembre de 1870, informadas las gentes de Pasto, acerca de los graves acontecimientos sucedidos en Roma relativos a la persecución del Papa por parte del Rey Víctor Manuel II y de Garibaldi, el sacerdote Rafael Cabrera a través de una Circular del Gobierno Eclesiástico y en hoja volante, dio aviso a los fieles de la celebración de una misa de rogativa en todas las Iglesias parroquiales de la diócesis para implorar la protección del cielo a favor del Sumo Pontífice Pío IX y del obispo Manuel Canuto Restrepo (Ortiz, 1935, pp.165-166).

\section{El obispo ungido por el Papa Pío IX}

El padre Restrepo fue consagrado el 3 de abril de 1871, a la edad de 45 años, por el propio Papa Pío IX, lo que le imprimió un carácter especial a su obispado. EI Papa, además, le donó un cáliz para Abejorral, su ciudad natal. Una vez hecho obispo tomó asiento en el Concilio y votó todos los decretos, hasta el último que declaraba la infalibilidad del Papa. Ahora con más fuerza, Restrepo, quien ya había dado muestras de liderazgo en sus parroquias y en sus actividades curiales, se constituyó en uno de los líderes más connotados de la Iglesia católica colombiana, se caracterizó por sus ardorosas polémicas contra el liberalismo; su defensa intransigente de la Iglesia fundada en el Syllabus; su radical postura favorable al partido conservador; y su fidelidad al Papado de Pío IX. Uno de sus principales biógrafos, lo ha comparado con Pablo de Tarzo porque como soldado de Cristo "vivió con ardor él buen combate" y "predicó con fuerza y valentía su palabra" (Agreda, 1998, pp. 107-146).

En vista de los acontecimientos que hicieron imposible la conclusión del Concilio, ya que el Vaticano fue tomado por las tropas de Garibaldi y el Papa fue hecho prisionero en la Sede de San Pedro (De Llorca, 1955, pp.652-654), y estando en ejercicios espirituales, el obispo Restrepo dirigió una Pastoral a sus diocesanos, desde Roma, en el mes de marzo de 1871. La Pastoral expresaba su condena al 
pensamiento liberal -por hereje, erróneo, ateo, fundado en la libertad y el progresoy su defensa a ultranza de la Iglesia como la única poseedora de la verdad (BRP, Restrepo, 1871b).

El obispo Restrepo llegó a la teológica y de tradiciones monárquicas, ciudad de Pasto (Gutiérrez Ramos, 2007; Bastidas Urresty, 1979; Ortiz Mesa, 1986, diciembre; Londoño, s.f.) en el sur de Colombia, a tomar posesión de su diócesis el 5 de marzo de 1872. Era el tercer obispo de Pasto en propiedad, después de José Elías Puyana y Juan Manuel García Tejada (Agreda, 1998, pp.389-390; Mejía Mejía, 1943, pp.163-250). Restrepo fue acogido por un amplio número de fieles católicos, quienes le hicieron un recibimiento apoteósico. Sin embargo, los estudiantes liberales del Colegio Académico, trataron de sabotear la solemne fiesta. Los discursos pronunciados en aquel día y en los siguientes en los banquetes que se dieron en su honor, las interpretaciones de las obras de Weber, Auber y Berbiguier y el estreno de Guillermo Tell, manifestaban el ambiente festivo y la aparente unidad de las gentes pastusas alrededor de su obispo, lo que fue expresado en un anónimo (Ortiz, 1935, pp.66-67) Pero este estado anímico duraría poco. El ambiente de entonces era bastante conflictivo en la ciudad, pues se trataba de un núcleo urbano de importantes tradiciones católicas que debió someterse a políticas liberales predominantes en el Estado del Cauca, del cual hacía parte al sur de dicho Estado. El descontento era evidente entre los conservadores por la aplicación la Constitución de 1863, por las pugnas entre los mismos liberales debido a que los radicales manipulaban el gobierno seccional. A la crisis política se asociaron las diferencias entre los partidos, los pronunciamientos de la plana mayor del conservatismo pastuso respaldado por la Iglesia católica, contra la implantación de la ley de instrucción obligatoria y laica en el Estado del Cauca (Ortiz, 1935, p.67), la creación y enfrentamientos entre sociedades republicanas y democráticas liberales con sociedades católicas, la pugna entre un grupo de conservadores y otro de liberales gólgotas, curiosamente, ambos apoyados por el obispo Restrepo, favorecedores de la independencia y autonomía de un Décimo Estado el del Sur con capital en Pasto (Almario García, Ortiz Mesa \& González, 1998; Vélez R., 1996, pp. 151-156) y los liberales mosqueristas, opuestos a la división del Estado, en razón del debilitamiento político y fiscal que representaría para Popayán, su capital, y para las élites liberales gobernantes.

La llegada del obispo a Pasto tuvo implicaciones inmediatas en la configuración de redes sociales, corporativas y partidistas. Así mismo, fue notoria la presencia del obispo en el ordenamiento de los comportamientos públicos y privados. Una vez posesionado, el obispo Restrepo fue nombrado miembro honorario de la Sociedad Filológica del distrito de Pasto, la cual se constituyó en un activo centro cultural que contaba con una importante biblioteca. En parte se trató de un reconocimiento social, pero al tiempo revelaba una virtud del obispo, la calidad de su léxico, su conocimiento y uso correcto del lenguaje, y una facilidad para producir una amplia literatura religiosa y política que fue resaltada más tarde por partidarios y opositores. También a partir de 1872 se ocupó de manera prioritaria de los pueblos de su jurisdicción, visitó escuelas y colegios, conversó con sus estudiantes, profesores y directores para analizar sus actitudes, niveles de preparación e ideologías, y fortalecer en ellos su catolicismo; ordenó a su clero asistir a ejercicios espirituales y lo sometió a exámenes, los cuales fueron aprobados por casi todos. Mediante un oficio del 31 de julio de 1872 al Vicario general, el obispo ordenó a todos los 
sacerdotes vestirse con corrección y decencia, "la que exige su santo ministerio, por más infeliz que fuera el pueblo donde residieran" (BRP, Restrepo, 1872, 31 de julio). Además, dispuso que no se celebrara el santo sacrificio de la misa donde no hubiera altar y enseres apropiados e indispensables, ciñéndose en todo al Concilio de Trento, e hizo destruir muchas imágenes y cuadros imperfectos, venerados en las iglesias y ordenó que se escogieran bellas y artísticas imágenes para los altares. El 2 de octubre de 1872 prohibió, bajo pena de suspensión, enterrar cadáveres en las iglesias, capillas y oratorios públicos y particulares (BRP, Restrepo, 1872, 2 de octubre). De tal modo que en el ambiente de una sociedad rural y predominantemente indígena, muy marcada por comunidades religiosas en el período colonial, el nuevo obispo fue afinando la simbología y el orden religiosos, y un estilo propio que reforzaba y afianzaría aún más las mentalidades católicas en la región.

\section{El obispo y el clero, especialistas en la guerra de la pluma: con firmas y anónimos}

En el caldeado ambiente de la Iglesia católica colombiana en la década de 1870, fue quizás el obispo de Pasto quien abanderó con mayor energía la resistencia al liberalismo, asumiendo una actitud directa y polarizadora. El 12 de octubre de 1872, dirigió a sus fieles una pastoral, en la que protestó de manera enérgica contra un decreto y una ley que, en su opinión, atacaban los derechos de la Iglesia; el decreto del $1^{\circ}$ de enero de 1870 emitido por el Poder Ejecutivo de la Unión, sobre instrucción obligatoria, que en su opinión debía llamarse "de corrupción obligatoria"; y la ley del 10 de junio de 1870, por la cual se rebajaba a la mitad-del 6\% al 3\%-el interés reconocido a la Iglesia por los bienes desamortizados (BRP, Restrepo, 1872, 12 de octubre). En la misma pastoral, monseñor Restrepo contó a grandes rasgos su viaje desde Europa y a través de Colombia para llegar a su diócesis y la manera afectuosa como fue recibido en todas partes, especialmente en el Cauca. En su última página aparece un grabado que representa las armas episcopales del Prelado; la figura completa de María Inmaculada se encuentra en el centro del escudo, el cual tiene una mitra a la derecha de su parte alta, que simboliza el poder y dignidad del Papa y del obispo; un báculo a la izquierda, símbolo de sostén y apoyo para la Iglesia; y una cruz en el centro de la parte alta del mismo. El clero reaccionó de inmediato y en su adhesión firmada por 30 sacerdotes y un subdiácono, respaldó totalmente la Pastoral del Obispo, considerando que:

el estado de la sociedad, en Colombia, es lamentable y vergonzoso, porque los enemigos de Dios, de su Cristo y de su Iglesia han zapado los fundamentos de la civilización católica; ora con la predicación impía y desenfrenada de la prensa; ora con los siniestros planes y acción perseverante de los clubes masónicos; y ora con las leyes y decretos atentatorios a la soberanía, libertad, derechos e independencia de la Iglesia de Jesucristo... (BRP, Cabrera y otros, 1872, 14 de octubre)

El apoyo masivo del clero pastuso estuvo acompañado de manifestaciones y adhesiones individuales de algunos clérigos de poblaciones del sur. Tales manifestaciones y adhesiones provinieron de sacerdotes de las más diversas parroquias y revelaban cierta unidad de criterios entre el clero de la región. Fueron los casos de Manuel Figueroa, cura párroco de la Unión, quien haría el sacrificio de su vida si fuera necesario; de Luis M. de Guzmán, cura interino de Funes; del clero 
del Municipio de Túquerres y de su párroco, Máximo Benavides; del cura de Jongovito, Manuel Santacruz; del padre José A. Idrovo, cura párroco interino de Nuestra Señora de la Natividad, del Tambo y otros, de José Ángel Delgado, cura de Tangua; de José Rosero, cura propio de Taminango; de José María de Guzmán, cura y Vicario de Barbacoas (Ortiz, 1935, pp.68-71). Al tiempo que el obispo recibía positivamente las adhesiones, publicaba otra Pastoral acerca de los graves acontecimientos políticos y religiosos de la época, en clara alusión a las dificultades por las que atravesaba la Iglesia frente al mundo moderno y ante las medidas liberales que atacaban sus fueros (BRP, Restrepo, 1872, 25 de noviembre).

La guerra de la pluma tuvo sus peculiaridades. Si bien, los respaldos mencionados a la Pastoral del obispo del 12 de octubre, revelaban un espíritu de cuerpo dentro del clero, los liberales por su parte, buscaron atacar las manifestaciones escritas de la Iglesia y aún suspenderlas y prohibir su impresión, circulación y lectura en algunas localidades. Las comunicaciones eclesiásticas eran bastante fluidas, las pocas imprentas fueron muy utilizadas y la transmisión de la información llegaba a los lugares más apartados en cumplimiento de sus objetivos, como Barbacoas, por ejemplo. La frontera con el Ecuador, fue también un punto de encuentro y de conflicto. En Túquerres, distrito limítrofe entre los dos países, el Inspector General de milicias, Peregrino Santacoloma publicó por bando un decreto que prohibía la impresión, circulación y lectura de Pastorales, Circulares y toda clase de Decretos Eclesiásticos. Un anónimo, producido probablemente por los opositores de Santacoloma, respondió que no aceptaría ese ataque a las libertades de palabra e imprenta garantizadas por la Constitución, pues no sería extraño que "con iguales facultades se nos prohíba hasta confesarnos, oír misa, invocar el nombre de Dios, y toda práctica religiosa". Por reacción, el anónimo invitaba a sus amigos y compatriotas a imprimir pastorales, circulares y decretos para darlos a conocer, leerlos y aplaudirlos "por sobre las barbas del señor Santacoloma" (Ortiz, 1935, p.71).

El ambiente político en el sur se fue caldeando porque el obispo Restrepo y los liberales mosqueristas entraron en choques permanentes sobre todo por el tema de la educación, asociado a contenidos políticos, religiosos y sociales. Aquél lo hizo desde el púlpito, los anónimos en hojas volantes y la prensa católica, además de sus Pastorales, Circulares, Decretos y Visitas pastorales; y aquellos, mediante similares mecanismos, el anónimo y el periódico principalmente, aunque la diferencia entre usar del púlpito y del confesionario al lado de la tribuna pública y la discusión libre, ponían en evidente desventaja a los liberales. Como en un juego de ajedrez, y buscando distanciarse de las polémicas directas con el gobierno caucano, el obispo Restrepo, produjo una Circular el 1 de diciembre, en la cual declaraba que no era autor de ninguna rebelión y que ni él ni su clero habían pensado en hacerle la guerra al gobierno. Sin embargo, la situación se puso más delicada, a tal punto que a fines de 1872, los jefes, oficiales y soldados conservadores del ejército del sur enviaron una hoja anónima a sus conciudadanos, en la que manifestaban estar en guerra abierta contra el Gobierno del Estado del Cauca en manos de los liberales; decían que abandonarían sus labores y hogares para rechazar la invasión que sobre Pasto quiere hacer el señor Santacoloma desde Túquerres, para conseguir jefes municipales de confianza de los pueblos del Sur y para conservar las armas "que son de exclusiva propiedad de los particulares" (Ortiz, 1935, pp.71-72). 
Por los trabajos de recolección documental realizados por Sergio Elías Ortiz, se puede colegir que el uso de anónimos fue de una alta frecuencia en Pasto, porque se trataba de una sociedad en la que los controles sociales ejercidos por parte de la Iglesia y de las comunidades religiosas fueron significativos, y el anónimo era el medio más expedito de expresión de una protesta, una reivindicación o una disidencia (Thompson, 1984, pp.173-238). Lo anterior se explica, en parte, porque Pasto fue una villa colonial cuya jurisdicción dependió de la muy católica Cuidad de Quito hasta mediados del siglo XIX, lo que le permitió albergar un alto número de comunidades religiosas que la hicieron proverbial en los siglos XVII y XVIII, al tiempo que aquellas ejercieron un amplio dominio en las densamente pobladas comunidades indígenas ubicadas en su entorno. En tales condiciones, desde las revueltas coloniales de 1765 en Quito, motivadas por alzas de precios en los productos básicos de la dieta cotidiana, pasando por las luchas de independencia, hasta llegar a las guerras civiles del siglo XIX, nada pudo moverse en Pasto sin la participación activa y decisiva de sus numerosas comunidades religiosas y de su clero secular. Allí se ubicaron también batallones fijos a fines del período colonial y élites civiles, cuyas propiedades en tierras y minas, debieron coexistir con las propiedades comunales indígenas, las tierras indias de resguardo y pequeñas unidades campesinas de mestizos. Así, las sociedades predominantemente indígenas pastusas, bastante tradicionales y creativas, se movieron entre el sometimiento y la resistencia ante las élites civiles, religiosas y militares; además, la sociedad pastusa se estableció cerca de la frontera colombo-ecuatoriana, donde se construyeron más espacios de encuentro que de conflicto, por tratarse de comunidades pertenecientes a sociedades con estilos de vida similares. Sin embargo, Pasto sufrió, por su carácter realista, su fidelidad al rey Fernando VII y su oposición radical a la independencia, unos niveles de represión altísimos de parte de los patriotas, lo que la hizo una ciudad más cuidadosa frente a su adversarios republicanos, muy prevenida frente a los cambios y bastante encerrada en sí misma (VV.AA., 1997-2000). En parte, por lo expuesto, sus gentes poseían características muy proclives a la vigilancia y la información acerca de los otros, un asunto muy corriente en sociedades indígenas. Por ello, en estas sociedades, pocas cosas pasaban desapercibidas. En este contexto se comprende el uso de anónimos y hojas sueltas para expresar ideas, protestar y disentir ante las conductas, comportamientos y actitudes oficiales dominantes o, aún, para ser puestos en circulación soterradamente por los propios grupos dirigentes.

\section{Sociedades liberales y católicas, periódicos y clero en la política}

Pues bien, el año de 1873 transcurrió entre tensiones, debido a las discusiones y enfrentamientos en torno al tema educativo, por el cual, pastusos masones-unos pocos intelectuales de la élite liberal que no obstante su número reducido se hacían sentir en la ciudad- se enfrentaron al obispo; también los cargos públicos disputados por los bandos liberal y conservador, fueron objeto de polémicas, pues los liberales lograron avances importantes en la ciudad conservadora de Pasto y, con ello, podrían impulsar la creación del Décimo Estado, otro de los temas de debate. Para llevar a cabo este último propósito, que liberaría a los conservadores, la Iglesia y los liberales anti-mosqueristas de la influencia y la dependencia de los gobernantes del Estado Soberano del Cauca con sede en Popayán, controlado por el mosquerismo y el radicalismo, era necesario idear mecanismos eficientes de organización, formación y movilización. Uno de esos mecanismos fueron las Sociedades Católicas 
- una modalidad de sociabilidad que se extendió con fuerza sobre todo en la década de 1870 (Arango de Restrepo, 2004b)-, las cuales debieron enfrentarse a sus contrapartes, las Sociedades Democráticas liberales, que fundadas entre 1847 y 1851, ahora estaban siendo rehabilitadas.

En el mes de noviembre de 1873, el obispo envió una Circular a los sacerdotes de su diócesis en la que de manera enérgica los llamaba a despertar del letargo y a quitarse la venda de los ojos que les había colocado "la secta masónica" y les impedía ver la maldad y el engaño del liberalismo; les instaba a que exhortaran e impidieran que los padres de familia y los propietarios siguiesen llevando sus contribuciones para sostener las escuelas en donde sus propios hijos iban a aprender a ser incrédulos, a despreciar las cosas de Dios y a perder la conciencia y el respeto por el cumplimiento de sus deberes humanos y religiosos. Así mismo, arremetió contra la prensa liberal "impía y desenfrenada y protegida por gobiernos ateos, materialistas y amigos de la Comuna de París (AAM, Repertorio Eclesiástico, 1874, 1 de enero, pp.271-273) y pidió a su clero incitar a sus fieles a retirar su apoyo a aquella prensa y a cambio suscribirse a las publicaciones católicas "que dicen la verdad con energía y sin rodeos, llaman las cosas por sus propios nombres, aunque no gusten a algunos, no admiten esa prudencia de moda, que solo sirve para sacrificar las mejores causas, y no hacen esponsión con la escuela liberal' (AAM, Repertorio Eclesiástico, 1874, 1 de enero, p.271) El obispo dijo a su clero que era necesario convocar a los fieles en tiempos de elecciones para que usaran de su derecho al voto y eligieran gobernantes católicos y honrados; también lo llamó a tomar parte directa en política porque era la única forma de sacarla de la corrupción en que se encontraba y, debía, a imitación de su Maestro, "arrojarla del templo é impedir sus profanaciones, so pena de renegar de su ministerio... porque si es cierto que no puede haber católicos liberales, también es una verdad que hay conservadores impíos, y estos son los peores enemigos que tiene la Iglesia, porque campean en ella con pasaporte falso" (AAM, Repertorio Eclesiástico, 1874, 1 de enero, p.271). Incitó igualmente a su clero y a los fieles, a orar por el éxito del Segundo Concilio Provincial que comenzaría el 8 de diciembre de 1872 y, finalmente, le ordenaba al primero leer su Circular durante dos domingos consecutivos.

En diciembre de 1873, el obispo emitió una Pastoral en la que nuevamente insistió en los puntos expuestos en la Circular anterior y enfatizó aún más la necesidad de la participación del clero en política, recogiendo las líneas centrales de la tradición de la Iglesia en un lenguaje coherentemente intransigente y dentro de un ambiente guerrero:

Los hijos de las tinieblas, que son más prudentes que los hijos de la luz... sostienen, apoyados por algunos pocos sacerdotes y por muchos católicos que el clero debe prescindir enteramente de la política... cuando los enemigos de Dios afirman y sostienen alguna opinión relacionada con los intereses y derechos de la Iglesia, la opuesta debe seguirse por los católicos, porque en ella está la verdad... (BRP, Restrepo, 1874, pp.1-2).

Pero, en sentido estricto, ¿qué significaba para el obispo Restrepo, que el clero tomara parte en política? En su opinión, los sacerdotes 
deben comprender las cosas y conocer los hombres públicos y sus doctrinas mejor que el pueblo puesto a su cuidado, aconsejar a su pueblo en la elección de un candidato que respete su religión y su fe, y de garantías de que no atacará los principios de la familia y de la propiedad; pueden y deben procurar, no solo el bien espiritual, sino también el temporal de los pueblos (BRP, Restrepo, 1874, p.3).

El Obispo no era partidario de que los sacerdotes convocaran a gentes de un partido a reuniones en sus casas o asistieran a ellas; tampoco que repartieran cédulas y llevaran de la mano a los hombres a las urnas eleccionarias, pues esto lo consideraba indigno de un sacerdote, aunque tal conducta no era, en su concepto, ni un delito ni un pecado. El sacerdote era pues, en su opinión, un orientador que debía enseñar al ignorante, dar buen consejo a quienes lo pidieran con derecho y necesidad, impedir que cayeran en errores, testimoniar públicamente a favor de la fe contra la incredulidad, de la virtud contra el vicio, de la verdad contra el error. Y dado que de los buenos gobernantes y de las buenas instituciones dependía en gran parte la felicidad temporal y eterna de los pueblos, el clero no obraba mal y cumplía su deber al procurar al pueblo buenos magistrados (BRP, Restrepo, 1874, p.3).

El obispo Restrepo recurrió también a figuras del Nuevo Testamento para mostrar de qué maneras las situaciones conflictivas y difíciles para la Iglesia se repetían a lo largo del tiempo. De allí que "la historia eclesiástica está llena de esos santos combates sostenidos en todos los siglos y en todas las naciones por los Obispos y sacerdotes contra la política impía e invasora de los gobiernos..." (BRP, Restrepo, 1874, p.6). Sin embargo, el obispo parecía olvidar o ignorar que la Iglesia vivió más en contubernio con los gobiernos desde el siglo IV, que en conflicto con ellos. El punto aquí era que se trataba de un gobierno en particular que dirigía los destinos de los Estados Unidos de Colombia, gobierno que era liberal y como tal, había tomado medidas que afectaban las tradiciones de la Iglesia católica. Por ello, con realismo político, consideraba el obispo Restrepo que:

...los decretos, constituciones y leyes emanadas de los gobiernos, son la expresión de su política, o, lo que es lo mismo, sus teorías políticas puestas en práctica e influyendo poderosamente en la educación, costumbres, derechos, intereses y creencias del pueblo... el tomar parte el clero en las elecciones no es ni puede ser delito, puesto que es un derecho constitucional y legal, y creemos que tampoco puede ser pecado puesto que el episcopado inglés, el francés, el alemán, el suizo, el español y el italiano dirigen con frecuencia su autorizada palabra al clero y a los católicos, exhortándolos a que usen de su derecho y cumplan su deber, trabajando para darse buenos gobernantes por medio de las elecciones... (BRP, Restrepo, 1874, pp.6-9)

En la segunda parte de su Pastoral, Monseñor Restrepo mostró como el progreso material si no se encontraba acompañado y tutelado por el progreso religioso y moral, no producía paz, sino guerra. Además sus posiciones revelan que para una sociedad como la colombiana de entonces era preferible ser pobre y atrasada técnicamente que rica e incrédula (Martínez, 2001, pp.431 y ss.). Es bien interesante mirar su lectura acerca de algunos países europeos que, según decía, dejaron de lado su progreso moral en aras de un progreso puramente técnico. Esta percepción nos ilustra acerca de su pensamiento, en dirección opuesta a un 
pensamiento liberal; nos muestra también a un hombre con buen nivel cultural y formación clásica en teología e historia; con una importante capacidad de argumentación; igualmente nos revela su profundo convencimiento de que la religión católica era la única e indiscutible y, que su doctrina, debía tomarse como criterio rector y verdadero del progreso material:

La España de San Fernando y de Isabel la Católica no conoció ferrocarriles, telégrafos ni ninguno de esos descubrimientos modernos; pero mientras fue digna del glorioso título de Nación católica, tuvo espíritu y patriotismo para batallar y vencer a sus enemigos y poseyó grandeza y gloria hasta tener, para dar a las ciencias y al comercio, un nuevo mundo. $Y$ la España liberal y atea de Castelar, Salmerón y tantos otros a ellos semejantes, con todos sus ferrocarriles y progresos modernos ¿qué tiene que ofrecer al mundo, sino sus bajezas, sus miserias y sus crímenes?...

La Francia de Carlomagno y de San Luis no imaginó siquiera que vendría el tiempo de los telégrafos... sin embargo fue grande y gloriosa porque tuvo fe, religión y moral. Y la Francia atea y burlona de Voltaire y de los Jacobinos solo supo ofrecer al mundo escándalos inauditos y levantar para sí... cadalsos, en que eran alternativamente inmolados las víctimas y los verdugos. $Y$ ¿qué es de la Francia incrédula y sensualista de Víctor Hugo y de Renán, de Julio Favre y de Gambetta, bajo la política revolucionaria e impíamente hipócrita de Napoleón III? Sus artes, su industria... le han servido apenas para pagar la deuda de millones contraída por su orgullo y su soberbia... para llamar con la velocidad del relámpago a los comunistas dispersos por toda Europa...

Y a la Italia tan grande por su comercio, sus artes y monumentos levantados bajo la influencia verdaderamente progresista y civilizadora del Pontificado Católico ¿de qué le sirven hoy sus progresos materiales en manos del liberalismo incrédulo? Sirven al gobierno ateo y francmasón para movilizar con rapidez sus hordas de bandidos y llevarlos a la ciudad capital y centro del catolicismo, Roma, aquella Roma cuyo solo nombre reúne los recuerdos de todo lo que ha habido de grande en el mundo... los del siglo de las luces no han respetado a Pío IX... Mejor y más honroso para Roma habría sido ser hollada por el caballo de Atila, que ser manchada por la planta inmunda de hombres como Víctor Manuel y Garibaldi, seguidos de su cola de libres-pensadores... (BRP, Restrepo, 1874, pp.6-9)

A esta Pastoral antiliberal y antimasónica, el periódico La Sociedad de Medellín, dedicó en el mes de abril de 1874, un editorial titulado "El Deber Político", en el que expresaba su complacencia al ver ratificadas por el prelado de Pasto las doctrinas que siempre había defendido acerca de los deberes de seglares y eclesiásticos de cooperar en las elecciones legales para nombrar legisladores y magistrados honrados y católicos. También respaldó la Pastoral en cuanto a la necesidad de que el progreso material estuviese siempre acompañado del progreso católico ( $\mathrm{La}$ Sociedad, 1874, 18 de abril, p.377). Este periódico se constituyó en la expresión más clara de la posición ultramontana y conservadora de la sociedad y la Iglesia católica antioqueñas.

En Pasto, los anónimos siguieron apareciendo y dejaban secuelas, molestias y posiciones radicales que podrían encausarse a través de formas orgánicas de expresión, pero al parecer éstas fueron pocas. El periódico El Centinela fue el 
órgano liberal de expresión y los documentos eclesiásticos lo fueron para la Iglesia. Precisamente a fines de 1873 apareció un pasquín en el pueblo de Ipiales que atacaba al obispo de la Diócesis, el mismo que fue respondido en términos similares por una hoja volante anónima de amigos del obispo:

Hemos visto un pasquín inmundo escrito sin duda por los ladrones del pueblo de Ipiales...estáis en vuestro derecho de vomitar veneno contra el señor Obispo de la Diócesis, pues creéis que al popularizarse sus evangélicas doctrinas, os arrebatarían lo robado; y en tal caso tenéis razón de defender la presa, al modo de los perros que se apoderan de su cadáver (Ortiz, 1935, pp.74-75).

De tal manera que el lenguaje violento fue la expresión normal para debatir las diferencias, las cuales evidentemente no quedarían resueltas de ese modo. De la guerra de la pluma y del lenguaje agresivo se pasaría pronto a la guerra en los campos de batalla.

\section{La Comuna de Pasto en una ciudad teológica}

El año de 1874 comenzó con visitas pastorales del obispo Restrepo a las poblaciones de Túquerres y Obando, donde fue recibido con "veneración y amor" (Ortiz, 1935, p.75). Los inicios de este año produjeron acontecimientos de suma importancia para comprender la "guerra de la pluma", que paulatinamente prepararía el terreno para "la guerra armada". Apareció en Pasto, la Comuna, según un anónimo titulado "La internacional" (Ortiz, 1935, p.75), un movimiento formado por el obispo Restrepo, apoyado por conservadores y por el gremio de artesanos, opuestos a las políticas del gobierno liberal caucano y, que buscaban desacreditar a los conservadores aristocráticos temerosos de las movilizaciones populares (Zambrano, 1989), por su ineficiencia en el manejo de la cosa pública; el nuevo movimiento quería competir con sus opositores en la arena electoral, defender las doctrinas de la Iglesia e independizar a Pasto del Cauca.

En sorna, el escritor Juan Montalvo -radical ecuatoriano exiliado en el surconsideraba la Comuna como "la presencia de supuestos comunistas en tierra de cristianos" (Ortiz, 1935, p.78). La hoja volante que informaba la aparición de la Comuna, decía también que en la noche del 18 de enero hubo "mueras" a la propiedad, la religión y la aristocracia, por lo que se reunieron numerosas personas en casa del conservador Dr. Juan B. Zarama, y se nombró una comisión, compuesta por los coroneles Manuel E. Barreda, Miguel Villota, Blas Santacruz y Felipe Rosero, para que dirigieran la defensa ante tales acontecimientos. Cuatro días más tarde, el 27 de enero, apareció una Manifestación firmada por los señores Ángel y Ramón Mideros, Manuel Narváez y muchos otros que pertenecían "a la clase del pueblo y dicen en su hoja que se les ha denominado 'La Comuna' porque en las noches del 11 y 18 del mismo mes han gritado vivas al Ilmo. señor Restrepo, al Jefe Municipal y a los hombres honrados del lugar" (Ortiz, 1935, pp.75-76).

Así pues, en el año de 1874 se evidenció una división dentro del conservatismo que gobernaba la ciudad de Pasto. Por su parte, la posición fundamentalista de Monseñor Restrepo que en un comienzo nutrió y unificó el conservatismo de Pasto, terminó por dividirlo; el partido conservador se fraccionó en dos grupos, uno llamado de los "nobles" y otro, del "pueblo". El obispo simpatizaba con el llamado "partido del 
pueblo", conformado por conservadores no aristocráticos, unos pocos liberales y los gremios de artesanos (Guerrero Vinueza, Andrade Á. \& Castro Chamorro, 1999, pp. 76-86). La mentalidad ultramontana del obispo estuvo a tono con las tradiciones religiosas que las comunidades masculinas -jesuitas, capuchinos, mercedarios, agustinos, franciscanos y Congregación de San Felipe Neri- y femeninas concepcionistas y clarisas- y los sacerdotes seculares, habían inculcado de tiempo atrás a las comunidades indígenas y a los artesanos, muy ligados a aquellas. El obispo había tenido diferencias muy fuertes con la "nobleza conservadora pastusa", debido a que no hacía reformas convenientes para las gentes del pueblo; en su opinión, "esa nobleza" hacía política de clientelas del mismo modo que los liberales y no lo respaldaban de manera decidida en contra de las tácticas que él utilizaba para atacar al liberalismo. Además, había tenido diferencias con sacerdotes del capítulo catedral acerca de las ideas sobre la fundación de la Comuna de Pasto. La situación que se vivió por aquellos días en la villa de Pasto, se expresó en libelos, pasquines y hojas sueltas de los bandos en contienda, los conservadores de "la nobleza pastusa" y los del bando del obispo. Los primeros pusieron a circular una hoja denigrando de los candidatos del "pueblo" y llamando a sus jefes, los de "La Comuna" (Dávila Muñoz, 1999, pp. 288-352), aludiendo con ello a la Comuna de París, sólo que aquí se trataba de una Comuna católica y conservadora, La Comuna de Pasto contra La Comuna de París. El obispo Manuel Canuto Restrepo respondió a aquel señalamiento con una carta en la que, además de su defensa, también se decía defensor de los sectores pobres y presentaba una mirada bastante congruente acerca de los desequilibrios sociales, los cuales consideraba, tenían su raíz en la injusta distribución de los bienes y riquezas, en una clase privilegiada que no tenía interés en que ésta situación se modificara, que a su vez no era muy respetuosa de la religión y ahora estaba representando los intereses de las clases altas pastusas y un puñado de radicales. En esa perspectiva, en el año de 1874, Monseñor Restrepo expidió una circular en la que expresaba al respecto:

apenas puede creerse que una ciudad que se gloría en llamarse a sí misma.... con el honroso título de "La Religiosa Pasto" pueda abrigar en su seno muchos hijos que, en vez de darle honor y nombradía, parece que se empeñan en exhibirla tristemente, en hacerla madre de desórdenes, centro de anarquía, teatro de farsas y abanderada de la Comuna... No ha habido, ni hay en Pasto tal Comuna...Si tal Comuna existiera en Pasto, sería preciso buscar las causas de su engendro y desarrollo, en esferas superiores a la que ocupa el común del pueblo... si hubiera más religiosidad y patriotismo prácticos en las clases favorecidas por Dios con el nacimiento, la educación y la fortuna; si se atendiera a la educación moral y religiosa de las clases desvalidas del pueblo... si se administra la justicia con rectitud e imparcialidad sin dejar inclinar la balanza... en contra del pobre y del desvalido...los pueblos vivirían morigerados con estos ejemplos y jamás traspasarían el límite que les señala la Religión... mas cuando no se hace esto... o se hace lo contrario, no hay por qué extrañar que de cuando en cuando la Comuna haga oír sus espantosos rugidos y muestre por algunos momentos su aterradora faz. (BRP, Restrepo, 1874, 22 de febrero)

Restrepo buscaba con este tipo de circulares atacar a sus adversarios, quienes en su opinión, o bien gobernaban sin sentido social y eran temerosos del pueblo -los conservadores "nobles"-, o bien, defendían las ideas de la Comuna de París -los mosqueristas-. Quería el obispo desviar la atención porque el movimiento de La Comuna sí existía y Monseñor Restrepo era un ardiente animador de ésta. La 
Sociedad de San Vicente de Paúl, que había sido fundada en la ciudad de Pasto en el año de 1870, con fines eminentemente benéficos y educativos, se transformó a partir del año de 1874 en una sociedad con objetivos políticos y de ella nació la asociación denominada "La Comuna de Pasto", integrada por el gremio de artesanos conservadores - de textiles, cueros, barnices y sombreros- quienes claramente se representaban a sí mismos como diferentes de la nobleza o de la élite conservadora, a la que acusaban de falta de liderazgo político. Esta nueva asociación utilizó panfletos y escritos anónimos para atacar a los conservadores elitistas y a los liberales mosqueristas, y se alió con los liberales antimosqueristas que favorecían una visión más popular de la política y más acorde con las posiciones de la Iglesia local. Aún más, al parecer, uno de los principales escritores de libelos y de hojas sueltas contra los "nobles" fue el mismo obispo Restrepo, pues por el estilo y formas gramaticales de muchos anónimos, estos provenían del obispo, solo que subrepticiamente y de manera clandestina. El obispo los escribía atacándose a sí mismo, y él mismo los respondía para defenderse y crear un clima de polémica en el cual pudiera ganar audiencia y respaldo. En el fondo de toda esta disputa lo que estaba en juego eran tres asuntos de máxima importancia: el enfrentamiento político-religioso en torno a la educación, el papel de la Iglesia frente al Estado laico y, la idea de crear el Décimo Estado del Sur, a fin de que Pasto y los distritos vecinos, libres de la tutela de Popayán, configuraran una nueva región, se separaran del Estado del Cauca y, así, la Iglesia se emancipara de la tutela del gobierno caucano y, especialmente, del Presidente liberal del Estado del Cauca, Tomás Cipriano de Mosquera. La Comuna era el mecanismo para lograr estos objetivos. Por ello, los opositores a este movimiento afirmaban que las cartas del obispo eran instrucciones para dividir los ánimos y hacer elecciones en las que sus adeptos obtuvieran la victoria.

Sin embargo, "La Comuna de Pasto", si bien cumplió un destacado rol en el alinderamiento partidista y en delimitar posiciones respecto a los intereses del obispo y de la Iglesia, no pasó de ser un movimiento político que no logró convertirse en alterativa partidista, debido a la división conservadora existente, a que muchos miembros no estuvieron de acuerdo con aliarse a los liberales antimosqueristas, y a que algunos consideraron que la creación del Décimo Estado desencadenaría una guerra fratricida. Además de las diferencias internas, La Comuna no llegó a constituirse en partido, posiblemente por el temor surgido entre "los miembros nobles" de la Sociedad de San Vicente de Paúl, de agrupar al gremio obrero y ponerlo en oposición con los grupos dirigentes de la población. Ese "gremio obrero" que no pasaba de ser artesanal, era bastante tradicional en sus estilos de vida y en sus mentalidades, pues como hemos señalado, fundaba sus proveniencias en comunidades indígenas muy "aculturadas" por el dominio español en ese territorio y por su obediencia a las directrices eclesiásticas, lo que encajaba perfectamente en las líneas de acción promovidas por el obispo. No obstante, "ese gremio obrero" era de temer por sus opositores, porque al fin y al cabo podía reaccionar ante los grupos de poder local, dependiendo de los niveles de polarización a que se llegara y de las posiciones del obispo y de sus seguidores inmediatos con respecto a los proyectos que defendían. En cualquier caso, el gremio artesanal mantuvo su expectativa y se puso a las órdenes del obispo, quien no fue más allá de los enunciados retóricos acerca de la inequitativa e injusta distribución de bienes y de denuncias sobre los desequilibrios sociales, para atacar a sus contrincantes, aunque en la realidad ello no se llevase a cabo. Las 
prevenciones de "la nobleza" siguieron estando presentes -por aquello ya tradicional desde la colonia, "el temor al pueblo" por parte de las élites, y pudieron resultar también de las "Manifestaciones" en las cuales se decía del alto número de gentes que participaba en los ejercicios espirituales dictados por el obispo (Ortiz, 1935, pp.80-81); o de hojas volantes de adhesión y respeto al obispo y expresión de sentimientos por su mal estado de salud, firmadas "por numerosas personas en su mayor parte del gremio obrero” (Ortiz, 1935, p.81).

Durante los últimos meses de 1874, la situación local estuvo cargada de enfrentamientos; la Corporación municipal liberal hizo cargos contra el Prelado ante la Delegación Apostólica residente en Quito -el antiguo centro jurisdiccional y eclesiástico de Pasto- por lo que los ánimos se caldearon y las expresiones de apoyo al obispo no se hicieron esperar (Ortiz, 1935, pp.85-86). Al tiempo, las divisiones partidistas también afectaron la aparente unidad de la Iglesia de Pasto, pues el cura de la Catedral, el padre José María Chicaíza, representante de "la nobleza conservadora", disintió del obispo en cuanto a los objetivos de la Comuna y a la partición del Estado del Cauca, por lo que fue destituido de su cargo después de ocuparlo por 25 años y debió ser trasladado a Popayán, a pesar del apoyo de sus fieles, entre los cuales aparecen numerosas mujeres firmantes de una hoja volante (Ortiz, 1935, p.86). En el mes de noviembre, la confusión en la ciudad con respecto a la Comuna llegó a tal punto que el obispo mismo debió sacar una Hoja volante "Al Público", para hacer claridad acerca del asunto e impresa en la Tipografía Ramírez el 12 de noviembre de 1874. Era una comunicación dirigida por el obispo Restrepo al cura de la Catedral, para que:

como corre la voz en Pasto, de que el Prelado fomenta con cartas el partido llamado la Comuna, compuesto de individuos que agitan la ciudad, fije por unos días esta nota en las puertas de la Iglesia, para que los que tengan tales cartas las entreguen y sean recibidas ante dos testigos que comparen sus firmas con la que acostumbra el Prelado. (Ortiz, 1935, pp.87-88)

El obispo devolvía a sus críticos la denuncia y la ponía en el terreno de las pruebas; esperaría entonces que tales pruebas apareciesen, de lo contrario todo ello sería el fruto del rumor y no de la comprobación. Así, ganaba terreno frente a sus adversarios. El 13 de noviembre, un día después de publicada la mencionada hoja volante, apareció otro anónimo que condenaba a los que formaban el núcleo de la Comuna de Pasto y exhortaba a los artesanos honrados a no dejarse seducir por los intrigantes, entre quienes se encontraba el obispo; dicho anónimo se titulaba "Un responso sobre los exánimes restos de la Comuna", también publicado en hoja volante por la misma Tipografía Ramírez (Ortiz, 1935, pp.87-88). Los mosqueristas buscaban con ello mantener en vilo al Prelado y no dejar que éste les ganara más adeptos entre los artesanos. Era tal la situación de expectativa en la ciudad que otro anónimo se dolía por la guerra de la pluma -"con que cuatro tinterillos destrozan la reputación de las personas"- e invitaba a la cordura, dado que Pasto, en su concepto, con el obispo que tenía, "ocupará un alto puesto en la civilización" (Ortiz, 1935, p.88).

Entre tanto, en el mismo año de 1874, el obispo Restrepo dedicó especial atención a la organización del Seminario de la Diócesis, a fin de ponerlo a tono con los dictámenes del Concilio de Trento y del Vaticano I; se comunicó con amigos en 
Europa para poner al frente del Seminario a los Padres Lazaristas. También, apoyado por padres de familia y por el Consejo municipal, trajo desde Quito, en diciembre de 1874, a los Hermanos Cristianos. De París importó la primera imprenta para la Diócesis, la cual fue muy útil en los años precedentes a la guerra civil de 1876-1877, pero desapareció con ella, al cerrarse y luego dividirse en partes que se vendieron. Continuó su Visita Pastoral por los pueblos de la región. Llama la atención que fue en Barbacoas (Jurado Novoa, 1990; López Rodríguez, 1989; Guerra A., 1980), una localidad de población negra y mulata, de tradiciones esclavistas, realista durante la independencia y, más tarde, liberal y mosquerista, cercana al mar Pacífico- donde la Visita Pastoral tuvo mejor recibimiento y mayor acatamiento. Allí, los liberales hicieron una visita al obispo y fueron muy bien recibidos por éste, según el decir de unos amigos suyos; se manifestaron respetuosos, finos y galantes con él, a tal punto que estaban curiosamente "desengañados de que el Señor Restrepo no es como lo habían pintado; es decir, un hombre banderizo, que no tenía en mira sino la revolución, y que para conseguirla se valía del influjo que a más de su talento, su instrucción y demás méritos personales le da la dignidad de Obispo" (Ortiz, 1935, p.89). A pocos días, el Obispo recibió felicitaciones de vecinos del Tambo por su Visita pero se dolían porque un reducido círculo de hombres ingratos trataban de dañar la reputación del prelado. Así pues, los respaldos al obispo en esta confrontación político-religiosa, fueron el resultado de una red que se amplió por localidades, gracias también a sus Visitas pastorales. Tales respaldos tuvieron muchas formas y provenían de múltiples lugares, instituciones, fieles y sacerdotes. Y al igual que en otras regiones del país, en Pasto fueron decisivas por sus labores, las Asociaciones del Sagrado Corazón de Jesús, cuya fundación se hizo en 1872 y para 1874, con sus fondos, sostenían una Escuela de 180 alumnas y socorrían a los pobres; y la Escuela Cristiana de Pasto, dirigida por los Hermanos de la Salle, que inició actividades con 150 alumnos y al culminar el local su número podría elevarse a 400 (Ortiz, 1935, p.89-90).

\section{1875: Una Iglesia en ascenso a pesar de los Democráticos}

El año de 1875 fue favorable a la Iglesia de Pasto en apoyos de comunidades religiosas y en el reconocimiento de los liberales por las obras religiosas promovidas por el obispo. Sin embargo, tuvo en las elecciones municipales y de Presidente del Estado y de la Federación, uno de los motivos más evidentes de tensión y desasosiego, y un destacado papel de las Sociedades Democráticas en la arena electoral. Los pasquines y anónimos siguieron siendo el pan de cada día con sus secuelas de incomodidad y bajeza. El Décimo Estado fue también un tema de interés. Veamos en detalle estos fenómenos.

Se estableció la Escuela de los Hermanos Cristianos y adquirió forma el Colegio Seminario en Pasto dirigido por los Lazaristas, pues el obispo consiguió el arribo a Pasto de la Congregación de la Misión para dirigirlo, según consta en dos hojas volantes (Ortiz, 1935, pp.90-92).

El 25 de enero, en la Revista El Católico apareció curiosamente una "Manifestación" anónima que trataba de la adhesión respetuosa y filial de la Municipalidad de Pasto a su Santidad Pío IX (BRP, Revista El Católico, 1875, 25 de enero). No obstante, los escándalos "contra nuestra santa religión" y contra el obispo también aparecieron, especialmente se supo por un anónimo que en la casa 
de Don Felipe Rosero, hicieron unos disfraces para remedar y ridiculizar al obispo y, luego, fueron a rematar a la casa del juez del Circuito Joaquín Guerrero (Ortiz, 1935, p.90). De tal manera que mientras unas instituciones funcionaban, las diferencias políticas continuaron manifestándose, polarizaban los bandos en conflicto y llevaban a expresiones de ridiculización del adversario. Llama la atención una manifestación de gratitud de la plana mayor del liberalismo pastuso, agradeciendo al obispo y felicitándolo por el establecimiento de los sacerdotes de San Vicente de Paúl y de los Hermanos de la Doctrina cristiana, "por el beneficio que recibirá Pasto con los nuevos planteles de educación" (Ortiz, 1935, pp.93-94), lo que muestra que el interés de estos liberales por la educación llegaba al punto de aceptar instituciones católicas, con tal que ofrecieran estudios útiles a la población.

Si miramos el fenómeno electoral, es notorio que se constituyó en uno de los principales elementos de polarización entre los partidos y las gentes del común, y ello tuvo incidencias dentro de la Iglesia, opuesta a candidaturas liberales. Evidentemente, los liberales pastusos fueron favorables a la candidatura del radical Aquileo Parra en 1875 y nada favorecedores de la de Rafael Núñez; además impulsaban a César Conto para la Presidencia del Estado del Cauca; y promovían candidaturas de liberales a la Legislatura y a la municipalidad utilizando el apoyo de las Sociedades Democráticas, así como las tradicionales formas coercitivas, presiones al electorado y amenazas de declaratorias de turbación del orden público y anulación de las libertades individuales, para obtener resultados favorables. No faltaron los pasquines liberales contra las actuaciones políticas de los dirigentes conservadores, quienes también lanzaron su lista de candidatos para diputados a la Legislatura, la cual apareció firmada por "Los Artesanos", mediante el anónimo "Al pueblo no se engaña", en coherencia con el tradicional movimiento de la Comuna, en el cual venían militando. La creación del Décimo Estado, con sede en Pasto, fue también tema en 1875, pero sus partidarios, destacándose las gentes de Ipiales, apenas se hicieron mención del mismo (Ortiz, 1935, pp.92-99).

En vista del fracaso de la Comuna, el obispo Restrepo creó una nueva sociedad que denominó "Unión Católica" (Guerrero Vinueza, Andrade Á. \& Castro Chamorro, 1999, p.87) la cual congregó a sacerdotes, plebeyos conservadores y antimosqueristas que no pudieron consolidar su alianza en el movimiento de La Comuna. La Unión Católica surgió pues como una sociedad política con fines exclusivamente partidistas dejando de lado las obras de beneficencia y el fomento de la educación, propias de la Sociedad de San Vicente de Paúl, y postuló a destacados miembros suyos como Diputados a la Legislatura en los comicios electorales de marzo de 1875, como se señaló anteriormente. Una de las manifestaciones simbólicas que expresaba la consolidación del Obispado "Pastopolitano" fue el traslado, en 1875, a la catedral de Pasto, con la respectiva exhumación del cadáver, del antiguo obispo José Elías Puyana (1860-1863), fallecido en Ambato el 20 de noviembre de 1864 "a causa de la persecución del gobierno radical", asunto pedido y obtenido por el obispo Restrepo al Arzobispo de Quito. En agosto, también fueron trasladados por orden del obispo, a la mencionada catedral los restos de los obispos de Pasto, Fray Antonio Burbano (1837), Mateo González Rubio (1841-1845), además del ya mencionado José Elías Puyana (Mejía y Mejía, 1943, pp. 93-159). 


\section{Disputas por la educación y guerra civil}

El año de 1876 comenzó con un ambiente caldeado y de tensiones entre partidos y dentro de fracciones de éstos y la Iglesia, lo que llevaría finalmente a la guerra civil, la cual comenzaría en el Cauca y se extendería por el sur y por otros Estados de la Unión (Guerrero Vinueza, 1996, junio, pp. 389-390). Para iniciar, la municipalidad de Pasto se enfrentó a los gobiernos del Estado del Cauca y de la Unión, en contra de sus medidas intervencionistas de organización, inspección y dirección de las escuelas primarias. Los liberales impulsaron la educación laica, fundaron periódicos en Pasto, Barbacoas e Ipiales y atacaron a sus contrincantes mediante sus Sociedades Democráticas, sus proclamas y anónimos. Por su parte, el obispo Restrepo afiló sus armas para defender los fueros tradicionales de la Iglesia, según "su leal saber y entender", a través de Circulares, Pastorales, Instrucciones, Anónimos, apoyo a fundaciones de escuelas católicas para neutralizar las escuelas laicas, impulso a la creación de revistas y periódicos católicos, fortalecimiento de Sociedades Católicas masculinas, uso del púlpito para agitar y promover entre los fieles la defensa de los derechos de la Iglesia que, en su opinión, les había conculcado el liberalismo, y ataque a las calumnias que confundían la opinión católica.

Todo se inició con la encarnizada lucha en torno a la aplicación de la ley 48 de 1875 que facultó al Gobierno Federal para organizar, inspeccionar y dirigir las escuelas primarias. Pedro Bucheli, vocal de la municipalidad de Pasto, informó que el Delegado del Departamento de Instrucción Pública del Cauca obligó al cumplimiento de dicha ley pero la municipalidad protestó ante el Estado y la Unión, porque la despojaba de una de sus atribuciones constitucionales (Ortiz, 1935, p.102). La educación se convirtió pues en uno de los principales campos de batalla. El 25 de febrero de 1876 ya se decía que el liberal José María Navarrete, salió de Pasto a visitar las escuelas primarias de los distritos según la ley 48 de 1875 y que "en esas escuelas está prohibida la religión a los niños". Por el estilo de la escritura, esta Hoja volante debió ser escrita por el obispo Restrepo, en opinión de Sergio Elías Ortiz (Ortiz, 1935, p.102).

Al tiempo que los liberales publicaban sus periódicos, El Sur Liberal, órgano del partido liberal de Pasto, en 1876 (BRP, El Sur Liberal, 1876-1879) y La Palestra de Barbacoas (BRP, La Palestra, Barbacoas, 1876), la Iglesia continuaba con su Revista El Católico, refundada en marzo de 1876 y editada en la Tipografía de Higinio Muñoz, la mayoría de cuyos artículos fueron escritos por el obispo Restrepo con la colaboración del padre Chicaíza, antes de ser suspendido en su cargo por aquel (Ortiz, 1935, pp.105-106). Se trataba de una publicación de combate contra el liberalismo y, al parecer, había salido como periódico a la luz pública en respuesta a la publicación del Decreto Ejecutivo de noviembre de 1870 sobre Instrucción Pública Primaria (Jaramillo Uribe, 1980, pp.79-121). En su primer número, la Revista empezó a publicar el Syllabus, lo que identificaba su bandera de guerra y el símbolo de nación creado por Roma y por la cristiandad, ante la bandera de guerra de los liberales: la Constitución de 1863 y la educación laica en este período (Arango de Restrepo \& Arboleda Mora, 2005, pp.87-155). La Revista fue acompañada por el establecimiento de escuelas normales, escuelas católicas de niñas y niños, promovidas por la Asociación del Sagrado Corazón de Jesús y el apoyo permanente de la Sociedad Católica de Pasto. Ésta última, respaldó la Pastoral del obispo del 31 
de marzo de 1876, con firmas de cerca de 500 individuos pertenecientes a ella. Se destacan sacerdotes y conservadores de las élites pastusas, tales como el Presidente de la Sociedad, el Pbro. Francisco de Paula Moncayo, el vicepresidente, los presbíteros Manuel M. Insuasti y José María Zambrano, Fray Estanislao Erazo, Blas M. Chaves, Antonio Zarama, Miguel M. Villota, Juan E. Moncayo, Emilio Chaves, Santos Ortiz, Maximiliano Chaves, Modesto Astorquiza, Juan Luis Bucheli, Juan Paredes, Ramón María Delgado y Manuel José Luna B. (Ortiz, 1935, pp.106107). La Sociedad se dio estatutos el 29 de abril de 1876, al parecer redactados por el obispo Restrepo según palabras de Sergio Elías Ortiz (BPR, Moncayo, 1876, 29 de abril, 12 p.).

También por aquellos días, el obispo atacó duramente la francmasonería (BRP, Restrepo, 1876, 14 de marzo) como uno de los principales males que carcomía, en su concepto, la sociedad pastusa en clara referencia a los masones liberales que se reunían periódicamente para hacer sus celebraciones y preparase para enfrentar el catolicismo y, sobre todo, para atacar la fuerza de las ideas del obispo "Trabuco" como llegaron sarcástica e irónicamente a nombrarlo. Los liberales más connotados en su ataque al Partido Católico, a la Sociedad Católica y al obispo, fueron Alejandro Santander, destacado jurisconsulto y profesor del Colegio Académico; Leonidas Puyana, político, militar, legislador y periodista; Pastor Enríquez, creador de la primera imprenta en Pasto; José María Guerrero y José María Navarrete. El maestro de la masonería en Pasto fue el mosquerista Pedro Marcos de la Rosa, uno de los fundadores de la Sociedad Filarmónica de Colombia en Pasto. También eran masones Manuel J. F. Córdoba, Agustín Ramírez y Alejandro Santander (Ortiz, 1935, pp.1-267).

Por su parte, los periódicos de Popayán, en especial El Programa Liberal, polemizaban continuamente con las publicaciones católicas; una de las más polémicas informaciones que publicó se refería a que el obispo Restrepo había permitido a su clero concurrir a dar lecciones de religión en las escuelas laicas que el gobierno liberal pretendía plantar en el suelo de Pasto (BRP, El Programa Liberal, 1876, 29 de abril). La respuesta aparecida en un anónimo en hoja suelta titulado ¡Alerta católicos del Cauca!, defendía al obispo, desechaba esa "procaz calumnia" y alertaba a los pastusos para que no se dejaran confundir por "los enemigos de la verdad" (Ortiz, 1935, p.109). Pero las polémicas fueron muchas más, como la que armó La Palestra de Barbacoas (BRP, La Palestra, 1876, 7 de mayo) contra una Instrucción Pastoral del obispo, muy probablemente a la que aludía la instrucción obligatoria que los sacerdotes debían dar a los niños, y el pecado que cometían los padres de familia que mandaran a sus hijos a las escuelas laicas (BRP, Restrepo, 1876, 28 de mayo, 8p.).

En este contexto, la Unión Católica se transformó en La Sociedad Católica de Pasto, con estatutos redactados por el obispo Restrepo, cuyo objetivo fue buscar el fortalecimiento del partido católico, y para ello se propuso crear Sociedades Católicas en toda la región del sur del Estado del Cauca (Valencia Llano, 1988, pp. 215-222). A través de éstas se generó un permanente reclamo por la independencia del Sur del Estado del Cauca, que dependía del norte sometido a Popayán. En este empeño, Pasto se convirtió en uno de los principales focos de sublevación y de disturbios contra el gobierno liberal seccional, por lo cual Tomás Cipriano de Mosquera declaró la guerra al que Ilamó "Partido Católico", utilizando 
como pretexto para ella, la oposición del obispo Restrepo a la Ley General de Educación promulgada por el régimen radical de la Unión. Las Sociedades católicas tuvieron pues una labor de agitación de ideas y de preparación de los conservadores para enfrentarse a cualquier medida liberal, y aún si fuere necesario, ir a la guerra. Fueron utilizados, por la mencionada Sociedad, todo tipo de actos que cohesionaran a sus adherentes en torno a estas ideas y prácticas (Arango de Restrepo, 2004a, pp. 329-355). En este ambiente, en el mes de junio, cuando los vientos de guerra ya se sentían, se celebró en Pasto la fiesta del XXX aniversario de la Consagración del Papa Pío IX -como decía la hoja volante escrita por Francisco de Paula Moncayo-, lo que revela claramente a qué le apuntaban la Iglesia pastusa y el conservatismo del lugar, y el fuerte simbolismo que ello implicaba. Una hoja volante avisaba "Se invitó al vecindario a celebrar el acontecimiento, se engalanó la ciudad con colgaduras y banderas en donde aparecía la inscripción "Honor a Pío IX", se celebró misa solemne en la Catedral con asistencia del obispo y autoridades, y se realizó una procesión que llevaría la imagen de la Santísima Virgen de la Concepción -tradicional en Pasto por la larga existencia de la Comunidad de las Religiosas Conceptas o Concepcionistas- y el retrato de Pío IX (Ortiz, 1935, p.110).

Del simbolismo religioso se pasó a la defensa del conservatismo y de la Iglesia. La guerra estalló en julio en el Estado del Cauca. La región de Pasto se vio envuelta rápidamente en ella. Del obispo sólo conocemos su circular del 12 de octubre de 1876, cuando ya la guerra había avanzado y los conservadores la perdían después de dos derrotas en el Estado del Cauca, en las batallas de la Granja y los Chancos, aunque todavía la situación de los conservadores pastusos era favorable a su causa. En la mencionada circular, el obispo aconsejaba elevar oraciones por las calamidades públicas y ordenaba una novena a la Santísima Virgen de las Mercedes en las diferentes iglesias de la ciudad (Ortiz, 1935, p.111).

\section{El obispo, excomulgado y expulsado del país por el gobierno radical, pastorea su rebaño desde el Ecuador}

En el mes de febrero de 1877, en plena guerra civil, el entonces Presidente del Estado del Cauca, César Conto, decretó la expulsión del territorio nacional de los obispos del Estado del Cauca, el obispo de Pasto, Manuel Canuto Restrepo, y el obispo de Popayán, Carlos Bermúdez, señalándolos como:

de los principales promotores de la rebelión contra los gobiernos de la Unión y del Estado y de la guerra sangrienta y desastrosa que tantos males está causando en el país; pues por sí y por medio de los curas y otros individuos de su clero promovieron, como es notorio, la formación de sociedades revolucionarias, se declararon en abierta pugna contra el gobierno y en flagrante desobediencia de varias leyes nacionales y del Estado... y viendo la guerra que una gran parte del clero hacía a las instituciones republicanas democráticas, varias sociedades de poblaciones importantes solicitaron del gobierno del Estado, desde antes de estallar la guerra, que expulsaran del Cauca a los Obispos y sacerdotes refractarios que promovían la rebelión... habiendo persistido dichos prelados y ministros, durante la guerra en la misma conducta de abierta hostilidad y rebeldía, la expulsión de ellos fuera del teatro de sus maquinaciones contra el gobierno es una medida de seguridad, de legítima defensa y aún de imperiosa necesidad y para el reposo público...(Diario Oficial, 1877, 4 de febrero) 
A las dos semanas de emitir este decreto, la Cámara de Representantes aprobó felicitar "al Gobierno Ejecutivo del Estado del Cauca por la acertada y justa medida que ha adoptado al decretar el extrañamiento de los Obispos" (Diario Oficial, 1877, 21 de febrero). Y en el mes de abril, el representante radical José María Quijano Wallis hizo un informe sobre el extrañamiento de varios Obispos, en un lenguaje tan incendiario como el de aquellos, y expuso sus apreciaciones sobre el obispo Manuel Canuto Restrepo, a quien trató de guerrillero, desestabilizador social, embrutecedor de los pueblos, "rebelde crónico, contumaz enemigo de la República, apóstol de matanzas, soldado disfrazado con el traje de sacerdote y revolucionario permanente" (Diario Oficial, 1877, 20 de abril).

La propuesta del Representante Quijano Wallis se convirtió más tarde en la ley 37 de 12 de mayo de 1877 por la cual se desterró del territorio colombiano por el término de diez años a los obispos Carlos Bermúdez, Manuel Canuto Restrepo, Joaquín Guillermo González y José Ignacio Montoya (Diario Oficial, 1877, 15 de mayo). Los Hermanos Cristianos y los padres Lazaristas fueron también desterrados. El obispo Restrepo volvió a aparecer a través de una nueva Pastoral el 17 de abril de 1877, después de la derrota sufrida por los conservadores del Estado de Antioquia el 5 de abril de ese año en Manizales. Todavía Pasto resistía a las tropas liberales. La Pastoral con el grabado de sus armas episcopales llamaba la atención sobre "el ambiente de impiedad que había producido los terribles saqueos de la ciudad de Cali", por parte del General liberal David Peña el 24 de diciembre de 1876 (Sinisterra, 1919); el destierro del obispo de Popayán, Carlos Bermúdez; el asesinato de García Moreno -presidente del Ecuador y defensor de la Iglesia Católica- y el envenenamiento del señor arzobispo de Quito, señor Checa y Barba en el Ecuador (BRP, Restrepo, 1877, 17 de abril). La adhesión y protesta del clero de Pasto ante la Pastoral del obispo fue inmediata, como también lo fueron las hojas volantes producidas por La Democrática de Pasto contra la participación del obispo, el clero y distinguidos conservadores en "la revolución que estalló en Pasto el 20 de julio de 1876" (Ortiz, 1935, p.112).

Los liberales, habiendo triunfado en Pasto, pusieron en acción sus proyectos educativos y sus programas de partido. El clero debió ocultarse, pero una red de vigilancia hizo que algunos sacerdotes fueran suspendidos por verse comprometidos con liberales en la celebración de sacramentos; otros mantuvieron informado al obispo de los sucesos cotidianos, mientras pudieron sacarlo a escondidas hacia el Ecuador (Ortiz, 1935, pp.113-114). Cuando se produjo la ley 37 de 1877, los obispos de Popayán y Pasto ya se habían fugado al Ecuador desde donde enviaron Cartas y Pastorales, las cuales fueron publicadas a través de las Sociedades Católicas; en ellas animaban al pueblo a resistir y a ser firmes en la defensa de la fe que profesaban. También desde el Ecuador, Restrepo envió una Pastoral en la cual ordenaba el cierre de la Catedral, las parroquias, capillas y oratorios públicos y privados, prohibía a los sacerdotes ejercer el ministerio en dichos lugares o fuera de ellos en el obispado de Pasto, pues en su opinión, era necesario dar una lección a las personas extraviadas y "que sepan todos los católicos que es al liberalismo incrédulo, tiránico y perseguidor de la Iglesia a quien se deben estos castigos y calamidades" (BRP, Restrepo, 1877, 8 de septiembre).

La guerra había producido desplazamientos forzosos, por lo que el jefe civil y militar del distrito de Quito informó, mediante un anónimo titulado "Hossana al 16 de 
septiembre" "firmado" por "Los Democráticos", al jefe municipal de Pasto, acerca de la internación de personas asiladas en la Provincia de Imbabura, así como la resolución de negarle asilo al obispo Restrepo (Ortiz, 1935, p.114). Al tiempo, el liberalismo pastuso, como otra iglesia, y con gran ironía, produjo un documento de antología que reveló el duro enfrentamiento que había tenido con el obispo Restrepo desde 1872, y que hacía evidente lo que representaron sus posiciones para el partido liberal en la ciudad, la región y el país. Siendo José María Guerrero, Jefe Municipal de Pasto, el 30 de septiembre de 1877, con letras latinas y a la manera como lo hacían los mismos jerarcas de la Iglesia, declaró "excomulgado contagioso o público" al obispo Manuel Canuto Restrepo. La hoja volante decía así con entonado acento:

Nos. José María Guerrero, por la gracia del Gobierno, Jefe municipal de Pasto, en nombre del pueblo y por autoridad de la ley... Por cuanto el ex Obispo Manuel Canuto Restrepo, alias 'Trabuco', olvidándose de la misión divina que el Espíritu Santo, dice le ha encomendado, según aparece de eso que él llama 'Entredicho' y en el que asegura que Nos le hemos perseguido con ferocidad salvaje, como también a su Vicario General, Cura de la Catedral \& compañía, atendiendo además, que el susodicho ex-Obispo, sin jurisdicción alguna, ha vomitado exabrupto desde el extranjero la lava inmunda que impropiamente llama sentencias, pretendiendo fascinar la atención de los miembros de su secta (los godo-fanático revolucionarios), sin saber que ésta ha renunciado a seguirlo porque ya ha conocido que la verdadera religión no se defiende a mano armada, que el titulado Pastor no es sino el lobo más sangriento y sanguinario; y Considerando...(aparecen tres considerandos), declaramos excomulgado contagioso o público- a Manuel Canuto Restrepo, -alias Trabuco, ex-Obispo de Pasto, reo prófugo, natural del porquerizo pueblo de Abejorral: lo declaramos separado del Gremio de la sociedad Colombiana, privado de las garantías constitucionales por toda su vida y expulsado para siempre del Municipio de Pasto, dé o no pruebas de haber mejorado su mala conducta, vuelva o no los doscientos mil pesos que se lleva indebidamente.

Constatan la autenticidad de este documento otros empleados del Municipio. (Ortiz, 1935, p.115)

\section{Defensores y detractores del obispo: entre su renuncia, aislamiento y triunfo durante la regeneración conservadora}

Conocemos pocas informaciones acerca de la vida del obispo en el Ecuador después de lo ya expuesto; sabemos del aviso de miembros del clero secular y regular al obispo sobre la derogatoria de la ley 37 de 1877 (Ortiz, 1935, pp.123-124); la renuncia a su cargo pedida por la Santa Sede al obispo, su aceptación por parte de la Santa Sede y la despedida de éste en impreso del Seminario de Pasto titulado "Un voto de gratitud" (Ortiz, 1935, p.124). Las comunicaciones de gratitud del clero, de localidades y de gentes cercanas al prelado fueron múltiples y provenían de buena parte de la geografía pastusa; los ataques de opositores al obispo por sus posiciones ultramontanas, su intransigencia y sus prédicas, siguieron vivos y se manifestaron incluso mediante denuncias ante el Tribunal de la opinión pública (Ortiz, 1935, pp.124, 127). Los defensores del obispo también se hicieron sentir, sobre todo en 1881 y ahora utilizaban las mismas armas usadas por su pastor y sus contrincantes, hojas volantes firmadas y anónimos provenientes de Yacuanquer, San Rafael de Tangua, Tambo, Túquerres y Pasto (Ortiz, 1935, pp.128-129, 133). 
El obispo Restrepo, desengañado y derrotado, por esos días recibió mensajes de Roma según los cuales sus posiciones fueron vistas como exageradas y excesivas en el nuevo contexto del Papado de León XIII. El obispo debió renunciar a su cargo presionado por este reclamo del Vaticano, por el respaldo que obtuvo el arzobispo Arbeláez del Papado, y por las reformas que la Iglesia se propuso para ponerse a tono con el mundo moderno, buscando un compromiso social ante los efectos negativos del capitalismo en la pauperización de sectores obreros y campesinos, y ante los avances del socialismo y el comunismo. Restrepo se retiró a vivir a Bogotá y luego a su pueblo natal, Abejorral; se desplazó luego a Guaduas, donde murió finalmente en el año de 1891. Si bien, aparentemente el obispo fracasó ante la derrota de los conservadores en la guerra civil de 1876-1877, no obstante su semilla cayó en tierra abonada, pues sus sucesores, especialmente el beato y luego santo, el obispo español Ezequiel Moreno, asumió las mismas banderas de Restrepo y luchó en la guerra civil de los Mil Días contra los liberales, financió tropas conservadoras e incitó a sus fieles al predicarles que "matar liberales no era pecado". De otra parte, el conservatismo y la Iglesia terminaron imponiendo sus reglas de juego en el período Regenerador, lo que fue muy bien visto por el obispo, quien debió disfrutar de este período hasta su muerte en 1891, al fin y al cabo él mismo había puesto su grano de arena en esa "reconstrucción política".

\section{REFERENCIAS BIBLIOGRÁFICAS}

\section{Fuentes documentales}

Actas y Decretos del Concilio Primero Provincial Neo-granadino. (1869). Bogotá: Imprenta Metropolitana.

\section{ARCHIVO DE LA ARQUIDIÓCESIS DE MEDELLÍN (AAM)}

Repertorio Eclesiástico, Diócesis de Medellín, Medellín, No. 34, 1 de enero de 1874, pp. 271-273.

\section{BANCO DE LA REPÚBLICA DE PASTO (BRP)}

Del Provisor y Vicario General Rafael Cabrera y otros. (1876, 14 de octubre). Adhesión que hace el clero de Pasto a la pastoral del Ilustrísimo Señor Obispo Diocesano, expedida el 12 de octubre último. Pasto.

El Programa Liberal. (1876, 29 de abril). Popayán, No. 24.

El Sur Liberal, Órgano del Partido Liberal del Sur. (1876-1879). Pasto: Imprenta de Santander Hermanos, por Sergio Solís.

La Palestra (1876). Barbacoas.

La Palestra. (1876, 7 de mayo). Barbacoas, No. 3.

"Manifestación". (1875, 25 de enero). Revista El Católico. Pasto.

Moncayo, Francisco de Paula. (1876, 29 de abril). Estatutos de la Sociedad Católica de Pasto, expedidos el 29 de abril de 1876. Pasto: Imprenta de Gálvez Hermanos, folleto, $12 \mathrm{p}$. 
Restrepo, Manuel Canuto. (1871a). Viaje a Roma y a Jerusalén, París: Imprenta de

Paul Dupont y Cía.

(1871b, 12 de marzo). Pastoral del llustrísimo Obispo de Pasto, Doctor Manuel Canuto Restrepo, Roma: folleto, s. p. de i.

(1872, 31 de julio). Oficio del señor doctor don Manuel Canuto Restrepo, Obispo de la Diócesis de Pasto. Pasto: s. p. de i.

(1872, 2 de octubre). Decreto del señor doctor don Manuel Canuto Restrepo, Obispo de la Diócesis de Pasto, Pasto: s. p. de i.

(1872, 12 de octubre). Pastoral que el Ilustrísimo Obispo de Pasto, Dr. Manuel Canuto Restrepo dirige a su clero y a sus diocesanos. Pasto: s. p. d. i.

(1872, 25 de noviembre). Pastoral que el Ilmo. señor Obispo de Pasto doctor Manuel Canuto Restrepo dirige a su clero y a sus diocesanos, acerca de los graves acontecimientos políticos y religiosos de la época. Pasto: Imprenta de Ramírez.

(1874). Pastoral del llustrísimo señor Obispo de Pasto, 8 de diciembre de 1873. Bogotá: Imprenta del Tradicionista, $15 \mathrm{p}$.

(1874, 22 de febrero). Circular del señor Obispo de Pasto, Manuel Canuto Restrepo. Túquerres: s. p. d. i.

(1877, 17 de abril). "Pastoral del Ilmo. señor don Manuel Canuto Restrepo, Obispo de Pasto". Pasto: Imprenta del Seminario.

(1876, 14 de marzo). Circular sobre la francmasonería. Pasto: Imprenta de Gálvez Hermanos.

(1877, 8 de septiembre). Pastoral del Ilmo. señor Obispo de la Diócesis de Pasto, Manuel Canuto Restrepo, Ibarra, s. p. de i.

Instrucción Pastoral del Ilmo. señor Obispo de Pasto. (1876, 28 de mayo). Pasto: Imprenta de Gálvez, folleto, 8 p.

\section{SALA DE PERIÓDICOS DE LA UNIVERSIDAD DE ANTIOQUIA}

Diario Oficial, Bogotá, No. 3894, febrero 4 de 1877; No. 3901, febrero 21 de 1877;

No. 3929, abril 20 de 1877; No. 3936, mayo 15 de 1877.

La Sociedad, Medellín, No. 96, abril 18 de 1874.

La Unión Católica de Antioquia, Medellín, 1856. 


\section{Fuentes bibliográficas}

Almario García, Óscar. (1998). "Las Provincias del sur (Nariño y Putumayo), -Aparte No. 10- La integración de la región y sus proyectos económicos y políticos: El proyecto vial y la salida al Pacífico y el ‘Decimismo'" En Almario García, Óscar, Ortiz Mesa, Luis Javier y González, Lina Marcela, Poder y Cultura en el Occidente colombiano en el siglo XIX: patrones de poblamiento, conflictos sociales y relaciones de poder. Antioquia y Cauca. 2 tomos Medellín: Universidad Nacional de Colombia, Sede Medellín, Colciencias.

Arango de Restrepo, Gloria Mercedes. (2004a). "Estado Soberano del Cauca: asociaciones católicas, sociabilidades, conflictos y discursos político-religiosos, prolegómenos de la guerra civil de 1876". En Ortiz Mesa, Luis Javier et al., Ganarse el cielo defendiendo la religión. Guerras civiles en Colombia, 18401902. Bogotá: Unibiblos.

(2004b). Sociabilidades católicas, entre la tradición y la modernidad. Antioquia, 1870-1930. Medellín: Universidad Nacional de Colombia, Sede Medellín y Dirección de Investigaciones, DIME.

Arango de Restrepo, Gloria Mercedes \& Arboleda Mora, Carlos. (2005). "La Constitución de Rionegro y el Syllabus como dos símbolos de nación y dos banderas de guerra". En Ortiz Mesa, Luis Javier et ál., Ganarse el cielo defendiendo la religión. Guerras civiles en Colombia, 1840-1902. Bogotá: Unibiblos.

Agreda, José Vicente, Pbro. (1988). "Manuel Canuto, Obispo de Pasto". En Manual de Historia de Pasto, tomo II, Academia Nariñense de Historia, San Juan de Pasto.

Bastidas Urresty, Edgar. (1979). Las guerras de Pasto. Pasto: Ediciones Testimonio.

Brew, Roger. (1971). Aspects of politics in Antioquia, 1850-1865. Oxford: Oxford University Press.

Dávila Muñoz, E. (1999). "Algunos antecedentes y fin de la Comuna Socialista de Pasto (1870-1874)". En Manual de Historia de Pasto, tomo III Pasto: Academia Nariñense de Historia.

De Llorca, Bernardino. (1955). "El Concilio Vaticano (1869-1870)". En Manual de Historia Eclesiástica. Barcelona: Editorial Labor S.A.

Duque Botero, Guillermo. (1974). Historia de Salamina, Vida municipal, siglos XIX y $X X$. Manizales: Biblioteca de Autores Caldenses, Séptima Época, tomo I, vol. 41.

Elías, Norbert. (1989). El proceso de la civilización. Investigaciones sociogenéticas y picogenéticas. México: Fondo de Cultura Económica.

González, Fernán. (2006). Partidos, guerras e Iglesia en la construcción del Estado nación en Colombia (1830-1900). Medellín: La Carreta histórica. 
Guerra A., Gonzalo. (1980). Tierra del oro. Reseña histórica de Barbacoas, Pasto: Imprenta Departamental.

Guerrero Vinueza, Gerardo León. (1996). "La confrontación político-religiosa en Pasto, durante el período del liberalismo radical, 1863-1878". En Manual de Historia de Pasto, tomo I. San Juan de Pasto: Academia Nariñense de Historia.

Guerrero Vinueza, Gerardo León, Á., N. M. ANDRADE \& C. E. CASTRO CH. (1999). Educación y Política en el régimen del liberalismo radical. Sur del Estado Soberano del Cauca, 1863-1880. San Juan de Pasto: Universidad de Nariño, Centro de Estudios e Investigaciones Latinoamericanas, CEILAT.

Gutiérrez Ramos, Jairo. (2007). Los indios de Pasto contra la República (18091824). Bogotá: Instituto Colombiano de Antropología e Historia.

Hobsbawm, Eric. (1989). La era del capitalismo (1848-1875). Barcelona: Labor.

Jaramillo Uribe, Jaime. (1980). "Decreto orgánico, Instrucción pública, noviembre 1 de 1870". En Revista colombiana de educación, No. 5. Bogotá: Centro de Investigaciones, primer semestre.

Jurado Jurado, Juan Carlos. (2008, Julio-dic.). "Reinventar la nación a través de la fe católica. De la religión, el clero y la política en la guerra civil de 1851". En Revista Historia y Sociedad, No.15. Medellín: Departamento de Historia, Universidad Nacional de Colombia, Sede Medellín.

Jurado Novoa, Fernando. (1990). "Esclavitud en la Costa Pacífica. Iscuandé, Barbacoas, Tumaco y Esmeraldas. Siglos XVI al XIX”, Colección Historia del negro en el Ecuador y sur de Colombia, tomo 3. Quito: Ediciones ABYA-YALA.

"Libros de los Macabeos". (1967). Biblia de Jerusalén. Bilbao: Editorial Española Desclée de Brouwer, S. A.

Lynch, John. (1991). "La Iglesia católica, 1830-1930", Bethell, Leslie (ed.), Historia de América Latina, tomo 8. Barcelona: Cambridge University, Crítica: "América Latina, cultura y sociedad, 1830-1930".

Londoño, Patricia. (Presentación) (s.f.). Pasto a través de la fotografía, Pasto 450 años. Bogotá: Banco de la República.

López Rodríguez, D. A. (1989). Las formas asociativas de la etnia negra minera de Barbacoas (Nariño). Medellín: Universidad de Antioquia, Departamento de Antropología.

Martínez, Frédéric. (2001). El nacionalismo cosmopolita: la referencia europea en la construcción nacional en Colombia, 1845-1900. Bogotá: Banco de la República.

Melo, Jorge Orlando. (1988). "Progreso y guerras civiles, 1829-1851". En Jorge Orlando Melo (Ed.) Historia de Antioquia. Medellín: Suramericana de Seguros. 
Molina, Gerardo. (1979). Las ideas liberales en Colombia, 1849-1914. 6ª Edición. Bogotá: Ediciones Tercer Mundo.

Ortiz Mesa, Luis Javier. (1985). El Federalismo en Antioquia. Aspectos políticos, 1850-1880. Bogotá: Editorial Gente Nueva, Universidad Nacional de Colombia, Sede Medellín.

(1986, dic.). "Participación de sectores populares en la Independencia de Pasto, 1809-1824". En Revista de Extensión Cultural, No 22. Medellín: Universidad Nacional de Colombia, Sede Medellín.

Ortiz, Sergio Elías. (1935). "Noticia sobre la Imprenta y las publicaciones del sur de Colombia”. En Boletín de Estudios Históricos, vol. VI, Nos. 66 y 67, suplemento No. 2. Pasto: Imprenta del Departamento.

Quijano Otero, José María. (1982). Diario de la guerra civil de 1860 y otros sucesos políticos. Bogotá: Incunables.

Rincón, Nemesio (1940). "Manuel Canuto Restrepo y Villegas, Obispo de Pasto", Desde la cumbre. Quito: Escuela Tipográfica Salesiana.

Sinisterra, Manuel. (1919). El 24 de diciembre de 1876 en Cali, narración de algunos de los principales acontecimientos ocurridos en esa fecha memorable, colección de artículos publicados en Los Principios de Cali. Cali: Imprenta de M. Sinisterra.

Thompson, Edward Palmer. (1984). "Delitos de anonimato". En Tradición, revuelta y conciencia de clase. Estudios sobre la crisis de la sociedad preindustrial. Barcelona: Editorial Crítica.

Tirado Mejía, Álvaro. (1989). "El Estado y la política en el siglo XIX“, Nueva Historia de Colombia, tomo 2. Bogotá: Planeta.

Uribe de H., María Teresa \& López Lopera, Liliana María. (2006). Las palabras de la guerra: Metáforas, narraciones y lenguajes políticos. Un estudio sobre las memorias de las guerras civiles en Colombia. Medellín: La Carreta Editores, Instituto de Estudios Políticos de la Universidad de Antioquia y Corporación Región.

Valencia Llano, Alonso. (1988). Estado soberano del Cauca. Federalismo y Regeneración. Bogotá: Banco de la República.

Vélez R., Humberto. (1996). "La disolución del Gran Cauca". En Alonso Valencia Llano (Dir.), Historia del Gran Cauca. Historia regional del suroccidente colombiano. Cali: Universidad del Valle, Instituto de Estudios del Pacífico.

Villegas Botero, Luis Javier. (1996). Las vías de legitimación de un poder. La administración presidida por Pedro Justo Berrío en el Estado Soberano de Antioquia, 1864-1873. Bogotá: Tercer Mundo editores-Colcultura. 
VV. AA., Manual de Historia de Pasto (1997-2000), 4 tomos. San Juan de Pasto: Academia Nariñense de Historia.

Zambrano, Fabio. (1989). "El miedo al pueblo. Contradicciones del sistema político colombiano (II)", Análisis 2, Conflicto social y violencia en Colombia. Documentos ocasionales, No. 53. Bogotá: CINEP.

Recibido: Septiembre 26 de 2011

Aprobado: Noviembre 29 de 2011 